\title{
Study on the Sustainable Development Model of Undergraduate Innovation Studio
}

\author{
Xiong Wei ${ }^{1, a}$, Wang Haijun ${ }^{2, b, ~}$, and Wan Runze, c \\ ${ }^{1}$ Wuhan Foreign Language School, Wuhan 430000, China \\ ${ }^{2}$ Hubei University of Education, Wuhan 430205, China \\ a38685709@qq.com, ${ }^{b}$ wanghaijun1977@126.com, ${ }^{c}$ runzewan@126.com
}

Keywords: undergraduate Innovation Studio, innovation practice, talent training, sustainable development.

Abstract: Aiming at the shortage of traditional software development mode of training talents, the advantages and disadvantages of creative studio learning model in talent training are discussed in this paper, and a sustainable development model of undergraduate Innovation Studio is introduced. Firstly, the theoretical study mode of combining practice and innovation is elaborated in detail. Then, the studio system construction, students' initiative and interactivity are combined to realize the cultivation of team spirit. Finally, the guidance and core role of the enterprise tutors in the students' studio is put forward to achieve a sustainable and virtuous circle for the development of innovative Studios.

\section{Introduction}

It is the core task for the development of higher education to deepen the reform of education and teaching and improve the teaching level, innovation ability and quality of personnel training in Colleges or universities. To realize the strategic goal of building a powerful human resource, it is necessary to improve the quality of education in order to support the development strategy of innovation driven development and the social development of service economy. Twenty-first Century is a new economic era of information and knowledge, and building an innovative country is the guarantee of the strength of science and technology. However, there are some misunderstandings in the innovation education of colleges and universities at present:

(1) The scientific innovation course system has not been established. In recent years, with the national emphasis on innovation and entrepreneurship education of college students, all universities also attach great importance to the innovation education for the students' professional guidance, but these courses have not formed a relatively perfect and independent system.

(2) Only pay attention to innovation and entrepreneurship Design Competition. In recent years, more and more innovative design contests are carried out attractively. In fact, there are much more difficulties in the innovation and entrepreneurship than in the innovation plan.

(3) The lack of innovation in teaching methods. The practical teaching of colleges is still confined 
to the traditional teaching methods, such as case analysis, classroom discussion and hands-on support, which results in the poor teaching effect.

(4) School-enterprise cooperation mechanism is too loose. The current school-enterprise cooperation mode often stays in simple form, which lacks sufficient dynamic adaptability in contrast with the enterprise’s order training mode.

\section{Deficiency of the current undergraduate Innovation Studio}

In the process of science and engineering professional training, practical ability and occupy important role. How to quickly and effectively cultivate students' practical ability in the project has been an important topic in aspect of the quality of personnel training. At present, most of colleges and universities promote the students to participate in the incubator and undergraduate studio in response to the national "public business innovation" appeal. Also, the students are actively encouraged to transform from "practice" to "practice research", then to provide support for China's high-tech enterprises cultivation and industrial development. Among them, as a new teaching mode, the establishment of innovation studios should be beneficial to give the students more opportunities to practice. The ultimate goal of learning innovation studio is to make professional knowledge serve the actual engineering project, and give the way for the students to truly realize how to translate the theoretical knowledge from into their own practical ability or apply it to the specific project development.

However, there exist many problems in the operation of the current innovation studio, mainly as following: (1) most of the rules and regulations of innovation studios is not established perfectly; (2) Lack of incentive mechanism for instructors and students; (3) the requirement of effective and systematic guidance for promotion of actual combat ability after students' attending the innovation studio; (4) Due to the constraints of space or facilities, Only a small proportion of undergraduate students can have an opportunity to join in the studio, which may lead to unfair education; (5) The studio is not a real company, and the relatively low credibility will make it difficult to obtain the real projects and fulfill the financial management or contract through the commercial negotiations; (6) Closed self-development and less opportunity to cooperate with enterprises.

\section{Sustainable development model of Innovation Studio}

Taking the construction and development of the studio of the Internet of things in Hubei University of Education as an example, this paper expounds the theoretical learning model of combining practice and innovation. Based on the above, the cultivation of students' initiative, studio system construction and interactive combination of team consciousness can be implemented. In addition, the enterprises tutors and school teacher cooperates at the core and leading role of students in the studio. Our research and practice will provide ideas for the development of innovative Studios.

The Internet of things is an important part of the new generation of information technology, and it is also an important stage of development in the "information" era. Due to the core of "Internet plus", the professional development in the future prospect is extremely broad. However, from the point of view of the training of professionals, the Internet of things is a cross subject, and its course is difficult to learn. Moreover, the practice process often requires the school to provide sufficient ground and equipment support. Therefore, compared with other majors, traditional talents training mode is hard to adapt to their needs. 


\subsection{Theoretical study model combining practicality with innovation}

Innovation ability mainly includes the observation, thinking, practice, communication and cooperation and other aspects. Therefore, cultivating innovative talents with professional networking should also pay attention to the cultivation of five kinds of abilities. The teachers need to organize the students of innovative studio to learn theoretical knowledge based on the project of lectures or discussions. The project based lecture mode mainly trains the students' ability to observe and think. The lecture for technical exchange should take the students as the main body and the teacher assists. Through the lectures, the students can more deeply understand the theory of knowledge, and improve their ability of observation and thinking ability. In addition, the project discussion mode will focus on the cultivation of students' thinking ability, practical ability and communication skills. The guiding teacher first chooses a practical case, and takes the case development process as the background, so that students can learn the theoretical knowledge involved in the case development process by way of free discussion. Then, by providing the corresponding development environment, the students can immediately practice and verify the theoretical knowledge involved, in which the problems can immediately be divergent discussion.

\subsection{Establishment of rules and regulations}

In order to realize the sustainable development of the innovative Studio development mode, the establishment of rules and regulations is the cornerstone. First of all, the studio system including management regulations, measures and regulations should be appraisal framework for internal management and activities in the studio. The members should carry out their duties, division of labor, regular meetings and discussion activities, so as to ensure the orderly operation of the studio. Build a work platform, strengthen the communication and interaction between the students' studios, and provide conditions for a healthy and effective competition and cooperation environment. The cultivation of the person in charge of the training studio should be intensified, and the comprehensive inspection should be launched regularly to ensure the responsible person with excellent quality and strong ability. Furthermore, the various functional organizations of the studio should be set up reasonably, and the financial supervision of the studio will be executed quarterly. In order to regulate all aspects of the work, the supervision and management of the studio should make use of scientific methods to formulate various rules. Eventually, with the enterprise management standards, we will establish and improve the student studio management system and evaluation architecture to achieve standard management and performance evaluation.

Secondly, the active and interactive combination of team awareness should be emphasized. Since the development of any project is fulfilled by a team, as a member of the development team, the communication and collaboration are also essential. By grouping students of different grades and different technical features into a team, we develop team awareness from two aspects: (1) Initiative team awareness training. Members in a team should first learn to communicate with other members voluntarily, and learn to analyze common problems together and solve problems cooperatively. (2) Interactive team awareness training. A good competitive mechanism between different teams can increase the interaction between teams. In order to compete for power projects, it can effectively cultivate student's cooperation ability, strain capacity and compressive capacity. Generally, the mutual learning between the students can effectively strengthen team spirit and their perseverance will be honed.

Next, the School's Educational Administrative Department should take measures to support the operation of the studio in aspects of Start-up funds and work site. Furthermore, under the premise of providing school professional mentors, we invite corporate mentors to participate in guidance, which 
makes full use of the advantages of professional tutors in teaching and the experience of enterprise tutors in project development. Teachers and students design topics and do researches on specific projects jointly. Also, it can provide to answer students' problems in a timely manner. How to attract a number of teachers with innovative and innovative ability and willing to guide the creative activities of the students' Studio? On the one hand, the college should bring about the mechanism and conditions of incentives for high level professional teachers to actively participate in the practice of innovative education student studio. On the other hand, the college should carry out a full cooperation with enterprises and be good at find the combination point associated with the vital interests of high level professional teachers to fully mobilize the enthusiasm of the professional teachers gradually. By actively encouraging professional teachers in many aspects of project training, comprehensive studio practice and graduation design, the teachers and students will get common development in practice.

\subsection{Industry-university-research cooperation}

We combine the service society with the model of industry-university -research cooperation, and try to explore the sustainable development mechanism of the innovation studio. The work of the studio will be transformed into the technical force needed in the development of the enterprise. In this way, the innovation studio will act as the carrier to mix together the gap between the curriculum standard and skills requirement in enterprise project, which can find a more suitable training model for professionals.

Taking the Internet of things studio as an example, the student team of IOT studio has undertaken many practical case productions, such as SCM technology and ARM programming technology. It provides a special teaching material for students to study themselves and prepare lessons for the teachers, thus stimulating the students' interest in learning. The student team of the studio participated in and completed the applications, including: Real-time monitoring system for critically ill patients based on MEMS Technology, Position detection system of simulated cloud platform, Fatigue driving detection system based on data fusion with multi MEMS sensor and anti child detention detection system in smart School bus, etc. Our innovation studio is supported by 2 provincial projects and 4 financial research project by Hubei ministry of education. So far, 3 patents and 2 applications for software copyright have been successfully applied. The students' team successfully applied for 2 projects of the Provincial College Students' innovation and entrepreneurship training program. Moreover, the student team's works participated in the national science and technology innovation competition, and won 12 national awards ( 2 of the first prize in the country) and twenty of the provincial awards (14 of the first prize in the provincial level). The works of our team are reported by dozens of media including Xinhua, NetEase news, Sohu, Phoenix website, Tencent Dachu network, China Daily, Changjiang Daily, Yangtze River Commercial Daily, Jinling Evening News, Chutian Metropolis Daily, Wuhan evening news and Wuxi TV station. By participating in classroom teaching links, scientific research projects, R \& D projects, self application projects and technological innovation competitions, the students' practical innovation ability has been significantly improved.

\section{Conclusion}

According to the drawbacks of traditional training of software development talent, we analyze the advantages and deficiencies in the Innovation Studio Mode, and put forward the sustainable development model of undergraduate Innovation Studio. Through the efforts of the past few years, the studio expands and enters a virtuous circle progressively, which guides the teachers to participate and expand the scale of students to organize more student teams gradually. By participating in the national competition and cooperation projects, the students can improve their ability effectively as 
well as undertake research projects. In the future, we will continue to improve the professional development and discipline construction by means of the exploration of innovation studio mode, and gradually form the perfect safeguard system of practice teaching.

\section{Acknowledgements}

This research is supported by the National Science Foundation of Hubei province, China (Grant No. 2017CFC819), Hubei Provincial Department of Education Scientific Research Programs (No. 2016419) and the Project of Hubei Co-Innovation Center of Information Technology Service for Elementary Education.

\section{References}

[1] Zhu wenya. On the construction of teaching quality monitoring system in entrepreneurship institute of universities and colleges [J]. Research in Higher Education of Engineering, 2016(4): 129-131.

[2] Zhou jian. Construction of the training mode of innovative and entrepreneurial talents in Colleges and Universities [J]. Journal of Yangtze University (Social Sciences Edition), 2011, 34(12): 141-143.

[3] Lv yingchun. Cultivation of innovation ability under the mode of Engineering Education [J]. Journal of Shenyang Normal University (Social Sciences Edition), 2013, 37(5): 84-87.

[4] Zhang jianping, zhang sujing. Discipline competition promotes the development of College Students' educational technology ability [J]. E-education Research, 2010(8): 36-41.

[5] Li Min, Chen Xingwen, Zhang Weiwei. Implementing Research based Teaching of Undergraduates Based on Studio Model [J]. Experiment Science and Technology, 2010 (8): 137-139. 